\title{
HUBUNGAN JARAK SUMBER PENCEMAR DENGAN KUALITAS MIKROBIOLOGIS AIR SUMUR GALI DI DESA PANGEBATAN, KECAMATAN KARANGLEWAS, KABUPATEN BANYUMAS TAHUN 2016
}

\author{
Frisian Lufti Intan Risqita ${ }^{1)}$, M.Choiroel Anwar ${ }^{2)}$ \\ Jurusan Kesehatan Lingkungan, Politeknik Kesehatan Kemenkes Semarang, \\ Jl. Raya Baturaden KM 12 Purwokerto, Indonesia
}

\begin{abstract}
Abstrak
Air yang dikomsumsi masyarakat haruslah bersumber dari mata air yang baik dan bebas dari pencemaran. Tujuan dari penelitian ini yaitu untuk mengetahui hubungan jarak sumber pencemar dengan kualitas mikrobiologis air sumur gali di Desa Pangebatan Kecamatan Karanglewas Kabupaten Banyumas Tahun 2016. Jenis penelitian yang digunakan adalah penelitian observasional analitik dengan pendekatan cross sectional. Pengambilan sampel dilakukan dengan metode cluster random sampling, keseluruhan sampel yang diambil adalah 34 sampel. Pengumpulan data dilakukan dengan cara observasi, wawancara dan pengukuran. Data dianalisis dengan statistik regresi yaitu menghubungkan jarak sumber pencemar dengan kandungan mikrobiologis (total Coliform) air sumur gali.Hasil pemeriksaan laboratorium diketahui kandungan mikrobiologis air sumur gali di Desa Pangebatan yaitu 34 sampel yang di periksa tidak memenuhi syarat kesehatan sesuai dengan ketentuan Permenkes RI .No: 416/MENKES/PER/IX/1990. Hasil analisis menunjukan nilai sig $(0,003)<\alpha(0,05)$ sehingga dapat disimpulkan ada hubungan jarak sumber pencemar dengan kualitas mikrobiologi air sumur gali di Desa Pangebatan, Kecamatan Karanglewas, Kabupaten Banyumas Tahun 2016.
\end{abstract}

Kata kunci $\quad$ : jarak sumber pencemar, kualitas mikrobiologis air sumur gali

\section{PENDAHULUAN}

Air merupakan salah satu sumber daya alam yang penting bagi kehidupan. Air adalah komponen lingkungan hidup yang sangat dibutuhkan bagi kelangsungan hidup manusia dan makhluk lainnya. Hal ini dibuktikan dengan keberadaan air dalam tubuh organisme. Sekitar $70 \%$ berat badan manusia terdiri atas air dan dalam badan air terdapat bendabenda hidup yang sangat menentukan karakteristik air tersebut, baik secara kimia, fisik, dan biologi (Soemirat, 2002).

Air yang dikomsumsi masyarakat haruslah bersumber dari mata air yang baik dan bebas dari pencemaran, karena itu untuk menjaga kualitas air agar layak dikomsumsi dan aman bagi kesehatan perlu ditetapkan dengan suatu standar. Penetapan standar air ini tergantung dari kegunaan air dan asal sumber air. Standar kualitas air bersih telah diatur dalam Permenkes RI. No: 416/MENKES/PER/IX/1990. Parameter kualitas air yang digunakan untuk kebutuhan manusia haruslah air yang tidak tercemar atau memenuhi persyaratan mikrobiologi, fisika, kimia, dan radioaktif. Untuk persyaratan mikrobiologis kadar maksimum total Coliform air perpipaan 10/100 ml sementara bagi air bukan perpipaan $50 / 100 \mathrm{ml}$.

Keberadaan air tanah dapat tercemar jika tidak dilakukan pengawasan dan pemantauan. Pencemaran air tanah akan berakibat buruk bagi kesehatan manusia. Pencemaran air di kota-kota besar telah

1) Email : frisianlufti@gmail.com

2) Email : irul1960@yahoo.co.id pencemaran tersebut berasal dari buangan industri tanpa proses pengolahan yang langsung dibuang kebadan air, disamping itu laju perkembangan penduduk yang cepat menyebabkan padatnya jumlah populasi dan pemukiman sehingga banyaknya pemakaian air, hal ini akan meningkatkan jumlah limbah cair yang dihasilkan dari pembuangan rumah tangga. Selain itu rendahnya kesadaran masyarakat terhadap sanitasi lingkungan, terlihat dari kebiasaankebiasaan masyarakat yang membuang kotoran/ faeces dan sampah ke sungai, kolam, selokan dan tanah. Menurut Widiati dan Kusnanto (2001) disebaigan besar negara, sumber pencemaran air dihasilkan dari limbah cair rumah tangga, limbah cair industri, saluran hujan air perkotaan dan limbah cair dari kegiatan pertanian.

WHO (Marsono, 2009) memperkirakan 80\% dari seluruh penyakit di dunia ini disebabkan oleh sanitasi yang buruk, air yang tercemar dan ketidak tersediaanya air. Diperkirakan sepertiga kematian di negara berkembang disebabkan oleh komsumsi air yang terkontaminasi. Data lainnya dari WHO menunjukkan sekitar 2,2 juta orang meninggal setiap tahunnya karena penyakit diare dan 10\% dari penduduk negara berkembang sangat rentan terinfeksi.

Menurut Widjaja (Marsono, 2009) Kejadian diare dapat ditularkan melalui air yang merupakan media utama dalam penularan diare, disamping makanan dan vektor penyakit. Diare dapat terjadi bila seseorang mengkonsumsi air minum, mencuci 
peralatan makan yang telah tercemar, baik tercemar dari sumbernya maupun tercemar selama perjalanan sampai ke rumah.

Menurut aturan Depkes (1995) Sumur gali harus ditempatkan jauh dari sumber pencemar. Apabila letak sumber pencemar lebih tinggi dari sumur dan diperkirakan aliran air tanah mengalir ke sumur, maka jarak minimal sumur terhadap sumber pencemar adalah \pm 11 meter. Sumber pencemar dapat berasal dari jamban, air kotor/comberan, tempat pembuangan sampah, kandang ternak dan sumur/saluran resapan.

Penyakit yang diakibatkan karena air salah satunya yaitu penyakit diare. Penyakit diare tertinggi berdasarkan data dari Dinas Kesehatan Kabupaten Banyumas tahun 2014 yaitu berada di Kecamatan Karanglewas dengan jumlah 1273 kasus dengan IR 202,5 per 10000 penduduk. Sedangkan berdasarkan laporan data penyakit yang menonjol di Wilayah Kerja Puskesmas 1 Karanglewas tahun 2014, diare merupakan penyakit tertinggi setelah penyakit ISPA. Jumlah kasus penyakit diare sebanyak 1273 kasus dengan IR 202,5 per 10000 penduduk. (Profil Puskesmas Karanglewas, 2004)

Berdasarkan data yang diperoleh dari Puskesmas 1 Karanglewas Tahun 2014, Desa Pangebatan adalah Desa dengan kasus diare tertinggi kedua di Kecamatan Karanglewas berjumlah 191 kasus dengan IR 30,1 per 1000 penduduk. Pada umumnya penduduk Desa Pangebatan menggunakan sumur gali sebagai sumber air bersih dan air minum. Jumlah sumur gali di Desa Pangebatan berjumlah 168 sumur.

Berdasarkan latar belakang tersebut, peneliti tertarik untuk melakukan penelitian dengan judul "Hubungan Jarak Sumber Pencemar Dengan Kualitas Mikrobiologis Air Sumur Gali di Desa Pangebatan Kecamatan Karanglewas Kabupaten Banyumas Tahun 2016”.

Tujuan penelitian ini adalah mengidentifikasi sumber-sumber pencemar air sumur gali, menggambarkan kualitas mikrobiologis air sumur gali, dan menganalisis hubungan jarak sumber pencemar dengan kualitas mikrobiologis air sumur gali.

\section{METODE PENELITIAN}

Jenis penelitian adalah penelitian observasional analitik yaitu peneliti ingin mengetahui ada tidaknya hubungan jarak sumber pencemar dengan kualitas mikrobiologis air sumur gali, dimana peneliti menggunakan pendekatan Cros Sectional. Penelitian ini dilakukan di Desa Pangebatan, Kecamatan Karanglewas, Kabupaten Banyumas. Penelitian dilakukan bulan Maret sampai bulan Mei 2016. Populasi yang digunakan dalam penelitian ini adalah seluruh sumur gali yang ada di Desa Pangebatan Kecamatan Karanglewas Kabupaten Banyumas pada Tahun 2014 yaitu sebanyak 168 sumur. Sampel yang digunakan dalam penelitian ini adalah 20\% dari seluruh jumlah sumur gali di Desa Pangebatan yaitu
$20 \% \times 168=34$ sumur gali dengan metode cluster sampling menurut Sugiarto dkk (2003, h90) adalah metode yang digunakan untuk memilih sampel yang berupa kelompok (cluster) dari beberapa kelompok dimana setiap kelompok terdiri atas beberapa unit yang lebih kecil. Kelompok-kelompok tersebut dipilih dengan menggunakan metode acak.

Parameter mikrobiologi dalam penelitian ini adalah parameter indikator tercemarnya air oleh bakteri Coliform. Pengamatan konstruksi sumur gali dan perilaku pengguna sumur gali dilakukan kepada sumur gali dan masyarakat pemilik sumur yang diambil sebagai sampel dengan menggunakan ceklist. Pengumpulan data jarak sumber pencemar dilakukan dengan menggunakan rollmeter. Dalam hal ini jarak sumber pencemar ke sumur gali dikorelasikan dengan kualitas mikrobiologis (kandungan bakteri Coliform) air sumur gali. Kondisi lingkungan fisik didukung dengan perilaku masyarakat. Untuk mengetahui adanya korelasi jarak sumber pencemar ke sumur gali dengan kualitas mikrobiologis (kandungan bakteri Coliform) sumur gali diolah dengan uji statistic Regresi, dengan $\alpha 5 \%(0,05)$, apabila $(\mathrm{Sig}<\alpha)$, Ha diterima, berarti ada hubungan jarak sumber pencemar ke sumur gali dengan kualitas mikrobiologis (kandungan bakteri Coliform) air sumur gali.

\section{HASIL DAN PEMBAHASAN}

Desa Pangebatan termasuk dalam wilayah Kecamatan Karanglewas Kabupaten Banyumas, mempunyai wilayah seluas 185,9200 ha, terletak di sebelah barat Kota Purwokerto (Kantor Bupati Banyumas). Secara topografis, Desa Pangebatan berada pada ketinggian $75 \mathrm{~m}$ dari permukaan laut (termasuk daerah dataran rendah).Desa Pangebatan terbagi dalam dua wilayah Dusun yaitu Dusun I di sebelah timur dan Dusun II di sebelah barat yang dipimpin masing.masing oleh seorang Kepala Dusun (Kadus). Sampai akhir bulan Desember 2012, Desa Pangebatan mempunyai penduduk sejumlah 5.928 orang terdiri dari 1.690 Kepala Keluarga (KK).

Berdasarkan hasil wawancara dengan 34 responden pemilik sumur gali yang diambil dari berbagai RW, diperoleh data responden yaitu data pendidikan responden tingkat SD sejumlah 24 (70,6\%), SMP 6 (17,6\%), dan SMA/STM 4 (11,8\%) dan data pekerjaan responden yaitu buruh 13 $(38,2 \%)$, tani $3(8,8)$, swasta $7(20,6)$ dan lainnya 11(32,4).

Menurut Departemen Kesehatan R.I. (1990, h.19), persyaratan kesehatan yang harus dipenuhi oleh sarana sumur gali khususnya mengenai jarak sumur gali yaitu Jarak sumur gali minimal 11m dari sumber pencemaran seperti jamban, air kotor atau comberan, tempat pembuangan sampah, kandang ternak serta tempat kotoran ternak. Berdasarkan pengukuran jarak sumber pencemar dengan sumur gali di Desa Pangebatan, Kecamatan Karanglewas, Kabupaten Banyumas Tahun 2016, yaitu dengan 
sampel 34 sumur gali yang diambil dari berbagai RW terdapat 5 sumber pencemar antara lain jamban, air kotor atau comberan, tempat pembuangan sampah, kandang ternak, dan sumur atau saluran resapan. Dari kelima sumber pencemar, air kotor atau comberan merupakan sumber pencemar yang jaraknya terhadap sumur gali paling tinggi dikategorikan tidak memenuhi syarat yaitu $100 \%$ jarak air kotor atau comberan ke sumur gali $<11$ meter. Semakin banyak sumber pencemar yang berada dalam jarak <11meter, semakin besar pengaruhnya terhadap penurunan kualitas mikrobiologi air sumur gali. Hal ini disebabkan karena semakin banyaknya bakteri yang mampu meresap ke dalam sumur.Variabel jarak jamban ke sumur gali didapatkan nilai mean sebesar 6,003, median 4,300, modus 3,0, standar deviasi 4,1754, nilai minimal 1,0 dan nilai maksimal 15,0. Pada variabel jarak air kotor atau comberan ke sumur gali didapatkan nilai mean 4,309, median 4,000, modus 3,1, standar deviasi 2,1279, nilai minimal 1,2, dan nilai maksimal 9,8.Variabel jarak tempat pembuangan sampah ke sumur gali untuk nilai meannya sebesar 6,053, nilai median sebesar 5,500, modus 4,0, standar deviasi 2,8572, nilai minimal 1,0 dan nilai maksimal 11,3. Sedangkan untuk variabel jarak kandang ternak ke sumur gali didapatkan nilai mean sebesar 8,400, median 7,550, modus 2,0, standar deviasi 5,6099, nilai minimal 1,0 dan nilai maksimal 15,7, dan variabel jarak sumur atau saluran resapan ke sumur gali didapatkan nilai mean sebesar 6,888, median 5,650, modus 4,0, standar deviasi 3,2327, nilai minimal 2,0 dan nilai maksimal 12,0.

Berdasarkan hasil pemeriksaan kandungan Coliform terhadap 34 sumur gali yang ada di Desa Pangebatan, sebanyak 34 sumur gali (100\%) kandungan MPN Coliformnya tidak memenuhi syarat, dengan hasil lebih dari 50 sel per $100 \mathrm{ml}$ sampel. Hal ini disebabkan karena banyaknya sumber pencemar dan jarak sumber pencemar ke sumur gali $<11 \mathrm{~m}$ sehingga sumur gali tercemar oleh bakteri Coliform. Sebagai alternatif untuk mendapatkan air bersih yang saniter adalah dengan pemberian kaporit yang dimaksudkan sebagai penjernih dan pembunuh mikroorganisme yang hidup di air sehingga air tersebut layak konsumsi. Adapun pemberian dosis kaporit dan cara menggunakan kaporit (desinfeksi sumur gali).Setelah dilakukan analisis statistik terhadap hasil kandungan Coliform didapatkan nilai mean 1702,18, median 2400, modus 2400 , standar deviasi 937,54, nilai minimal 94, dan nilai maksimal 2400. Hasil analisa statistic uji regresi sebgai berikut:

Tabel 1 Hasil Uji Regresi Hubungan Jarak Sumber Pencemar Dengan Kuaitas Mikrobiologi Air Sumur Gali Di Desa Pangebatan Kecamatan Karangewas Kabupaten Banyumas Tahun 2016.

\begin{tabular}{|r|r|r|r|}
\hline \multicolumn{1}{|r|}{$\mathbf{R}$} & R Square & \multicolumn{1}{c|}{ df } & \multicolumn{2}{|c|}{ Sig } \\
\hline $.680^{\mathrm{a}}$ & .463 & 5 & 0,003 \\
\hline
\end{tabular}

Berdasarkan Tabel 1 diperoleh nilai sig $(0,003)<$ $\alpha(0,05)$ sehingga dapat disimpulkan terdapat hubungan jarak sumber pencemar dengan kualitas mikrobiologi air sumur gali di Desa Pangebatan, Kecamatan Karanglewas, Kabupaten Banyumas Tahun 2016.

Tabel 1 juga menjelaskan besarnya nilai korelasi/ hubungan (R) yaitu sebesar 0,680 dan dijelaskan pula besarnya prosentase pengaruh variabel independen terhadap variabel dependen yang disebut koefisien determinasi yang merupakan hasil dari penguadratan $\mathrm{R}$ dari output tersebut diperoleh koefisien determinasi $\left(R^{2}\right)$ sebesar 0,463 , yang mengandung pengertian bahwa pengaruh variabel independen (jarak sumber pencemar) terhadap variabel dependen (kualitas mikrobiologi air sumur gali) adalah sebesar 46,3\%, sedangkan sisanya dipengaruhi oleh variabel yang lain. Adapun variabel lain yang mempengaruhi antara lain:

\section{Konstruksi Sumur Gali}

Pembangunan sumur harus mengikuti standar kesehatan. Bangunan fisik sumur yang tidak memenuhi standar akan mempermudah bakteri meresap dan masuk ke dalam sumur. Menurut Djasio Sanropie (Tutut, 2015) persyaratan konstruksi sumur gali adalah sebagai berikut: Dinding sumur harus kedap air sedalam $3 \mathrm{~m}$ dari permukaan tanah untuk mencegah rembesan dari air permukaan,Bibir sumur harus kedap air setinggi 0,5-0,7 $\mathrm{m}$ dari permukaan tanah atau garis batas banjir, untuk mencegah rembesan air bekas pemakain kedalam sumur, Dinding sumur gali dengan pemasangan batu bata atau batu kali dibuat dengan pemasangan batu kosong dimulai dari dasar sumur sampai pada dinding kedap air diatasnya yaitu pada kedalaman $3 \mathrm{~m}$ dibawah permukaan tanah, guna mengalirkan air tanah kedalam sumur, Lantai sumur dibuat kedap air, jarak tepi lantai sampai tepi luar sumur $1 \mathrm{~m}$, tebal lantai minimal 0,20 m dari tanah, dan bentuk lantai sumur bujur sangkar atau lingkaran, SPAL dibuat kedap air sepanjang $10 \mathrm{~m}$ dari tepi lantai sumur.Hasil penelitian untuk variabel konstruksi sumur gali terdapat 30 (88,2\%) sumur gali dengan konstruksi sumur gali tidak memenui syarat dan 4 (11,8\%) sumur gali dengan konstruksi sumur gali memenuhi syarat.

\section{Perilaku Pengguna Sumur Gali}

Ada beberapa cara pengambilan air sumur gali yang memungkinkan terjadinya pencemaran. Hal ini dapat dikendalikan atau dicegah dengan cara pengambilan air seperti pengambilan air dengan menggunakan timba yang selalu terjaga kebersihannya, tali timba dan ember tidak tergeletak di lantai (tergantung), jika pengambilan air sumur gali memakai alat lain misal pompa tangan atau listrik, sumur di beri lubang ventilasi untuk mencegah pengotoran sumur, bibir sumur tidak boleh 
untuk meletakkan barang-barang seperti alat dapur, cucian pakaian kotor yang memungkinkan pencemaran, dan lantai diusahakan selalu kering serta tidak terdapat genangan air atau sampah serta kotoran lain yang terdapat dipermukaannya. Hal ini jika tidak diperhatikan maka akan menimbulakan dan menyebabkan gangguan kesehatan seperti bau tidak sedap, tempat sarang vector, serta dapat menimbulkan gangguan pada pemandangan atau nilai estetika (Indonesia, Depkes 1991, h.14).

Berdasarkan hasil penelitian terhadap 34 responden yang mempunyai sumur gali di Desa Pangebatan, Kecamatan Karanglewas, Kabupaten Banyumas teknik pengambilan air sumur gali $100 \%$ telah sesuai dengan tata cara pengambilan air sumur gali yang baik yaitu menggunakan kerekan lebih tinggi dari bibir sumur , namun terdapat 44,1\% pengguna sumur gali yang kondisi ember dan tali embernya tidak selalu menggantung yaitu diletakkan diatas bibir sumur sehingga memungkinkan terjadinya pencemaran. Maka ember dan tali ember harus diletakkan menggantung agar tidak memungkinkan terjadinya pencemaran. Dari 34 responden yang mempunyai sumur gali di Desa Pangebatan, Kecamatan Karanglewas, Kabupaten Banyumas tidak ada yang memakai pompa tangan, $58,8 \%$ responden memakai pompa listrik tetapi timba atau kerekan masih mereka pergunakan.

Pemeliharaan kualitas sarana sumur gali harus dilakukan dengan baik agar tidak cepat rusak atau terkotori. Seperti merawat, memperbaiki dan membersihkan sarana sumur gali. Berdasarkan hasil penelitian pada 34 sampel sumur gali terdapat $100 \%$ ember yang rusak selalu diperbaiki atau diganti dengan ember yang baru, 73,5 \% dinding yang tidak di perbaiki dan 32,4\% bibir sumur gali yang tidak diperbaiki. Dinding dan bibir sumur gali yang rusak harus diperbaiki kembali dengan cara diplaster kembali menggunakan semen agar dinding dan bibir sumur tetap kedap air. Terdapat lumut pada ember dan lantai, ember yang berlumut harus selalu dibersihkan dan lantai yang berlumut juga harus dibersihkan agar lantai tidak licin.

\section{Arah aliran air tanah}

Pencemaran air sumur gali oleh bakteri koliform dipengaruhi arah aliran air tanah. Pergerakan air tanah yang mengandung bakteri koliform mengarah ke sumur gali, menyebabkan air sumur gali tercemar oleh bakteri koliform.

\section{Porositas dan permeabilitas tanah}

Porositas dan permeabilitas tanah akan berpengaruh pada penyebaran bakteri koliform, mengingat air merupakan alat transportasi bakteri dalam tanah. Makin besar porositas dan permeabilitas tanah, makin besar kemampuan melewatkan air yang berarti jumlah bakteri yang dapat bergerak mengikuti aliran tanah semakin banyak.

Curah hujan
Air hujan mengalir di permukaan tanah dapat menyebarkan bakteri Coliform yang ada di permukaan tanah. Meresapnya air hujan ke dalam lapisan tanah mempengaruhi bergeraknya bakteri Coliform di dalam lapisan tanah. Semakin banyak air hujan yang meresap ke dalam lapisan tanah semakin besar kemungkinan terjadinya pencemaran. Pada musim hujan tingkat Escherichia Coli meningkat hingga 700 koloni per $100 \mathrm{ml}$ sampel air dibandingkan dengan musim kemarau karena kemungkinan kontaminasi air sumur dengan limpahan septic tank. Air dapat melarutkan berbagai bahan kimia yang berbahaya dan merupakan media tempat hidup berbagai mikroba, maka tidak mengherankan bila banyak penyakit menular melalui air.

\section{Jumlah pemakai}

Sebagaimana dinyatakan pada stratifikasi Puskemas bahwa jumlah pemakai sumur individu adalah 5 jiwa. Makin banyak jumlah pemakai sumur berarti semakin banyak air diambil dari sumur yang berarti berpengaruh juga terhadap merembesnya bakteri Coliform ke dalam sumur. Banyaknya jumlah pemakai sumur juga mempengaruhi kemungkinan terjadinya pencemaran sumur secara kontak langsung antara sumber pencemar dengan air sumur, misalnya melalui ember atau tali timba yang digunakan.

\section{Umur sumur}

Sumur yang telah digunakan cukup lama dan volume air yang diambil relatif banyak, menyebabkan aliran air tanah di sekitar sumur semakin mantap dan mendominasi. Selain itu sumber pencemar yang ada di sekitar sumur juga semakin banyak sejalan dengan perkembangan aktivitas manusia. Hal ini memberi peluang lebih besar terhadap merembesnya bakteri koliform dari sumber pencemar ke dalam sumur. Sumur yang digunakan dalam waktu yang relatif lama lebih besar kemungkinan mengalami pencemaran, karena selain bertambahnya sumber pencemar juga lebih mudahnya sumber pencemar merembes ke dalam sumur mengikuti aliran air tanah yang memusat ke arah sumur.

\section{Kedalaman permukaan air tanah}

Kedalaman muka air tanah merupakan permukaan tertinggi dari air yang naik ke atas pada suatu sumuran. Ketinggian permukaan air tanah antara lain dipengaruhi oleh jenis tanah, curah hujan, penguapan, dan keadaan aliran terbuka (sungai). Kedalaman muka air tanah akan berpengaruh pada penyebaran bakteri Coliform secara vertikal. Pencemaran tanah oleh bakteri secara vertikal dapat mencapai kedalaman 3 meter dari permukaan tanah.

\section{SIMPULAN DAN SARAN}

Berdasarkan hasil penelitian dan pembahasan dapat diambil simpulan yaitu terdapat 5 sumber 
pencemar air sumur gali di Desa Pangebatan, Kecamatan Karanglewas Kabupaten Banyumas Tahun 2016 yaitu jamban, air kotor atau comberan, tempat pembuangan sampah, kandang ternak dan saluran/sumur resapan.

Kualitas mikrobiologi (MPN Coliform) air sumur gali di Desa Pangebatan, Kecamatan Karanglewas, Kabupaten Banyumas Tahun 2016 $100 \%$ tidak memenuhi syarat.

Terdapat hubungan ( $\mathrm{R}^{2}$ sebesar 46,3\%) jarak sumber pencemar dengan kualitas mikrobiologis air sumur gali di Desa Pangebatan, Kecamatan Karanglewas, Kabupaten Banyumas Tahun 2016.

Saran yang ditujukan Pemerintah dan Sanitarian Puskesmas I Karanglewas yaitu memberikan penyuluhan kepada masyarakat tentang sanitasi (jarak sumber pencemar ke sumur gali yang memenuhi syarat kesehatan, kualitas mikrobiologis air sumur gali dan cara penggunaan sumur gali) dalam rangka meningkatkan taraf kesehatan dibidang kesehatan lingkungan dan pemantauan sanitasi sumur gali dan pemeriksaan kualitas mikrobiologis air sumur gali secara berkala, dan saran yang ditujukan kepada masyarakat yaitu masyarakat harus benar-benar memperhatikan keadaan sanitasi di sekitar sumur gali, dengan selalu menjaga kebersihan dan memperbaiki konstruksi sumur gali yang rusak agar tetap dalam keadaan bersih sehinga tidak mempengaruhi kualitas air sumur gali.

\section{DAFTAR PUSTAKA}

Aris Santjaka, 2011, Statistik untuk Penelitian Kesehatan, Yogyakarta: Nuha Medika.

Budiman Chandra, 2007, Pengantar Kesehatan Lingkungan, Jakarta: Penerbit Buku Kedokteran EGC.

Desvita, 2000, Hubungan Jarak Sumber Pencemar, Kondisi Fisik Sarana dan Perilaku
Terhadap Kualitas Air Sumur Gali di Keparakakan, Yogyakarta, Tesis, Yogyakarta: Universitas Negeri Yogyakarta.

Djasio Sarropie dkk.,1983, Penyediaan Air Bersih, Jakarta: PT Rineka Cipta.

Hefni Efendi, 2003, Telaah Kualitas Air Bagi Pengelolaan Sumber Daya Dan Lingkungan Perairan, Yogyakarta: Kanisius.

Marsono, 2009, Faktor-Faktor Yang Berhubungan Dengan Kualitas Bakteriologis Air Sumur Gali di Pemukiman Desa Karanganom, Kecamatan Klaten Utara, Kabupaten Klaten, Tesis, Semarang: Universitas Diponegoro.

Soemirat Juli, 2001, Kesehatan Lingkungan, Jogjakarta: Gajah Mada University Press.

Sri Mukti Suhardini, 2005, Hubungan Jarak dan Kualitas Fisik Sumur terhadap Jumlah Koliform dan Kadar Zat Organik di Sekitar Peternakan Babi dan Industri Tahu di desa Ngestiharjo, Kecamatan Kasihan, Kabupaten Bantul, Yogyakarta,Tesis, Semarang: Unuversitas Diponegoro.

Sugiarto dkk, 2003, Teknik Sampling, Jakarta: PT Gramedia Pustaka Utama.

Tutut Mugi Rahayu, 2015, Studi kualitas air bersih sumur gali di Dusun Japun Desa Kewangunan di Kecamatan Petanahan Kabupaten Kebumen Tahun 2014, Karya Tulis Ilmiah, Purwokerto: Politeknik Kesehatan Kemenkes Semarang Jurusan Kesehatan Lingkungan Purwokerto. 